than to repeat other anaesthetics within short periods ?" but left it to be assumed that this was not in question, though no data exist by which the point could be answered-with the unfortunate outcome which we have noted. The statement ${ }^{6}$ by the Medical Research Council restores some balance to the situation and the council seeks to support research designed to answer this question. The problem will not be resolved easily, since a lengthy list of possible contributing factors will have to be considered in designing an effective prospective trial.

Those with responsibility for ethical consent to clinical research should not themselves prejudge an issue so clearly unclear in an endeavour to protect the public from one speculative danger while simultaneously favouring the use of anaesthetics other than halothane-which can carry greater overall intrinsic dangers for patients.

\footnotetext{
1 Mansell-Jones, D., CSM/AR/S/121, 3 January 1974.

2 Inman, W. H. W., and Mushin, W. W., British Medical fournal, 1974, 1, 5.

3 Bunker, J. P., et al., The National Halothane Study. Washington, U.S. Government Printing Office, 1969.

4 Mushin, W. W., et al., British Medical fournal, 1971, 2, 18.

'Robson, J. G., and Norman, J., British Medical fournal, 1974, 1, 516.

British Medical fournal, 1974, 3, 268.
}

\section{Hair of the Dog}

Everyone will have come across the chap in the saloon bar who insists that the only cure for a hangover is a stiff drinka hair of the dog that bit you. An American gastroenterologist, J. R. Hoon, has recently investigated this bar-room myth using a gastrocamera and two volunteers who were undergoing repeated endoscopy in the course of another study. His interest was aroused by a young man who turned up one morning after an alcoholic binge saying "if my stomach looks like my eyeballs, you are really going to see something!" Having noted an excess of gastric mucus and increased motility, Dr. Hoon was not content merely to admire the view and decided to administer gin. Within a few minutes the stomach had relaxed and was much easier to examine. Unfortunately, there appears to be a shortage of volunteers with hangovers in Wisconsin and it was six years before the study could be continued; another young man was found to have a disturbed and jumpy stomach which was calmed by whisky. However, it was not clearly stated that the hangover symptoms improved, and the mechanism of action of the alcohol was not investigated, so the gastrocamera findings must continue to tantalize the drinking public until they are confirmed.

Before every alcoholic reaches for another bottle in the morning he should be reminded that endoscopic appearances may bear no relation to clinical symptoms. This is certainly true of gastritis-a word conspicuously absent from the American paper, which is all the more surprising since alcoholic gastritis is usually assumed to be the underlying gastric lesion in inebriates. However, the omission may have been a master stroke; because the mere mention of gastritis to gastroenterologists is a recipe for a heated emotional disagreement. Transient alteration in secretion, congestion, and ready bleeding were noted by Wolf and Wolff ${ }^{2}$ in Tom's gastric fistula-appearances which could well be interpreted as gastritis but in this case were induced by feelings of hostility and resentment. Furthermore it is unlikely that any two endoscopists would agree on the presence or absence of gastritis, and it is even less likely that a pathologist would confirm their findings. Perhaps we should be looking at changes in mucus secretion and motility instead.

A word of caution must also be given to all those would-be investigators who are reaching for their endoscopes. It is now common practice to give intravenous diazepam as premedication. Unfortunately, young men who are regular heavy drinkers are more than usually resistant to this drug; when the dose is increased they merely become more uncooperative and less inclined to follow the examiner's instructions. One of the major contra-indications to endoscopy may, therefore, be a steady alcoholic intake of more than four pints $(2 \cdot 21)$ of beer per day. Such patients are often powerfully built, owing to manual labour, and young enough to retain strong teeth. They are the most frequent cause of the common but unpublicized complication of endoscopy, damage to the fibrescope.

1 Hoon, J. R., fournal of the American Metical Aswociation, (1974), 229, 184
2 Wolf, S., and Wolf, H. G., Human Gatric F',!cti ".. London. Oxford University Press, 1947.

\section{Women in Medicine}

The first woman to qualify in medicine in Britain was Elizabeth Garrett, who obtained the diploma of the Society of Apothecaries in 1865. The universities lagged behind in the admission of women to medical degrees, but Edinburgh awarded a degree to Sophia Jex-Blake in 1876. By this time the General Medical Council had accepted women as registered medical practitioners, ${ }^{1}$ and it is worth recalling that the vote for women and their eligibility to sit in Parliament did not come until 1918 , and even then they had to be over 30 years of age and fulfil certain conditions. Changes in the social order take time and a receptive climate of opinion to make them acceptable.

The persistence of generations of women is getting them ever closer to equality of status and opportunity with men in medicine (and other professions). There is still some inequality, but it seems to be diminishing. In 1973 figures from the Universities Central Council on Admissions (U.C.C.A.) ${ }^{2}$ showed that $32 \%$ of those accepted to read for medicine were women compared with only $21 \%$ in 1966 . Recently feminists and others have argued that the proportion of women reading medicine should be $50 \%$, and deans have been criticized for operating a quota system. There is no evidence to support this charge. In $197230.5 \%$ of all home candidates applying for medicine were women. Over the whole country this does not suggest sex discrimination but it does argue that there may be preselection in schools. As the numbers of women applying to medical schools has increased the deans have responded by taking more of them, and in the proportion in which they apply. No one who understands the U.C.C.A. system would believe that any dean would be so devious as to work out the proportion of female applicants beforehand and adjust his or her entry to suit.

In the past it might have been possible to argue that women were not physically or emotionally capable of dealing with the horrors of medicine and particularly surgery. Miss Nightingale's nurses in the Crimea must have helped to shatter those illu- 
sions. Nor can it any longer be argued that women are intellectually inferior to men. Indeed there is evidence that women in general have better A level grades on entry to medicine and that they qualify more often with honours and with no failures in the final examinations, ${ }^{4}$ though again this might be due to the preselection in schools.

The argument commonly advanced against increasing the entry of women to medicine is the economic one. The cost of producing a doctor is estimated as being between $£ 15,000$ and $£ 20,000$, most of which falls on the taxpayer. Flynn and Gardner ${ }^{5}$ analysed the output of women graduates from the Royal Free Hospital School of Medicine between 1945 and 1964 and found that $15 \cdot 1 \%$ of their sample of 1,055 were not working in medicine and $33.6 \%$ were working only part-time. Over the past few years it has been accepted that about $25 \%$ of women doctors under the age of 65 are not working in medicine, compared with a figure of $3 \%$ for men. The present annual output of doctors from British medical schools is just over 4,000, rising to just over 5,000 in the next decade. If 2,000 of these are to be women and present trends continue the equivalent of 500 of them may not practise except for a very short time. This could mean a loss on the investment of approximately $£ 1$ million per annum-and it is also the output of about three or four fair-sized medical schools, a greater loss than that due to emigration, said to be about $10 \%$ per annum, though many emigrant doctors return.

The loss of these women to medicine is essentially due to marriage and family responsibilities. Flynn and Gardner found that of their single women only $1.7 \%$ were not working and $4.7 \%$ were working part-time. Of those with children over the age of 18 years $8 \%$ did not return to medicine. It seems, however, that those graduating in the later years of the survey were more able to cope with the dual responsibilities of a medical career and a family-possibly reflecting a change in cultural attitudes. A similar survey by Aird and Silver ${ }^{6}$ from the Middlesex Hospital Medical School found that though women at the undergraduate stage are academically superior to males they obtain fewer higher degrees and diplomas and fewer consultant posts.

The branches of medicine which women choose are general practice, public health, family planning, anaesthetics, pathology, paediatrics, and a few are in research, psychiatry, and other disciplines. This could represent a choice by women because of differing aptitudes and inclinations, but it is more likely that these are selected because they offer a chance to combine the two careers of medicine and family. And here is the crux of the matter. Those who opt for two careers cannot normally expect to reach the highest points in medicine. They must be satisfied with achieving less in medicine than they would have done had they foregone marriage and family and devoted themselves to medicine full-time. It is a marvel that against all the odds so many women perform incredibly well in both careers. But surely freedom of choice should be preserved. There will be those who wish to be full-time doctors and those who wish to be full-time family women, and there is nothing reprehensible in either choice freely made. Those who wish to combine the two careers should be helped more than they have been.

It used to be thought that continuing care of patients could not be a part-time job. Now this principle has been shown not to hold by the introduction of set off-duty time for all but consultants and by extra duty payments. It is tacitly accepted that patients are treated by teams of doctors and not by one personal doctor all the time. Women who can work only parttime can now be included fully in the teams; it is a question simply of adequate organization. Experience has shown that when such women are included in the teams part-time they usually do more than is specifically required of them in terms of extra duty and even in residence. ${ }^{6}$ There is inertia yet to be overcome, but the return of women to medicine is possible after their family commitments have been reduced.

While her children are young a woman doctor can use the retainer scheme, ${ }^{78}$ under which a woman below the age of 55 may receive $£ 50$ per annum provided that she will undertake 12 paid clinical sessions, attend seven educational sessions, retain her registration, and subscribe to a medical defence society and an appropriate medical journal. ${ }^{8}$ The object is to keep her in touch with medicine so that at a later date she may be able to take advantage of the women doctors' retraining scheme introduced in 1969. The way in which this has worked in the South-west Metropolitan Regional Hospital Board has been described by Essex-Lopresti. ${ }^{6}$

Neither of these schemes seems to be as widely known among women doctors as it should be. Perhaps all the regions have not shown the same enthusiasm in putting them into operation, and women doctors could exert some pressure on their local postgraduate deans and regional medical officers. Another difficulty not yet solved is the provision of specialist training on a part-time basis so that while their children are small women can progress up the ladder towards consultant status.

Those stridently calling for equality in medicine might well pay some attention to the facts and then direct their attention to more intransigent defenders of male prerogatives. They are pushing against a door that is almost wide open. There is no selection bias against women in medicine. It is accepted that women are academically better than men in the undergraduate years, at least at present until the academically able may be diluted, and there is an organization available which will allow women not only to be retained in medicine but to be retrained at a time in their lives suitable to them and in places near their homes. They can therefore have the best of both worlds if they wish to strive for them as so many have done and are doing. But let the element of choice remain, so that not even moral coercion is applied to those who do not wish to conform.

\footnotetext{
1 Guthrie, D., in A History of Medicine. London, Thomas Nelson and Sons Ltd., 1945.

2 Universities Central Council on Admissions, 1973.

3 Universities Central Council on Admissions, 1972.

4 Stanley, G. R., and Last, J. M., British fournal of Medical Education, 1968 , $2,204$.

5 Flynn, C. A., and Gardner, F., British fournal of Medical Education, 1969, 3,28 .

Essex-Lopresti, M., Lancet, 1970, 2, 204.

7 Eskin, F., British fournal of Medical Education, 1974, 8, 141.

8 Department of Health and Social Security. The Women Doctors' Retainer Scheme, H.M. Circular 72(42). London, H.M.S.O., 1972.

9 Department of Health and Social Security, Re-employment of Women Doctors, H.M. Circular 69(6). London, H.M.S.O., 1969.
}

\section{Recovery from Heroin Addiction}

The generally accepted view that heroin has a high addictive potential and that addicts have extreme difficulty once hooked in stopping use of the drug has been challenged in a study by Robins et al. ${ }^{1}$ from Washington University School of Medicine. In a very careful study, nearly 1,000 army enlisted men who had returned to the U.S.A. from Vietnam in September 1971 were sought for interview and collection of urine specimens. Of these 470 represented the general population of enlisted men, and 495 were a sample of those whose urines 